\title{
Offline/online brand element transmutation and tangible/intangible product characteristics within various South African retail brand categories: An exploratory study
}

\author{
H. Kruger and L.C.H. Fourie* \\ Graduate School of Business, University of Stellenbosch \\ PO Box 610, Bellville 7535, Republic of South Africa \\ hpienaar@belpark.sun.ac.za and Lchf@usb.sun.ac.za \\ N.S. Terblanche \\ Department of Business Management, University of Stellenbosch, \\ Stellenbosch 7600, Republic of South Africa \\ nst@sun.ac.za
}

Received March 2005

\begin{abstract}
The aim of this study is firstly to investigate if offline/online brand transmutation (uniform/non-uniform) patterns are particular to certain retail categories. Secondly, to determine if product characteristics (tangibility/intangibility; high cost, low frequency/low cost, high frequency; high potential for differentiation/low potential for differentiation) and brand transmutation is dependent or independent. Thirdly, given a particular product characteristic and brand transmutation is dependent, to establish the significance of the dependence effect. Two hundred and eleven South African retailers, divided into sixteen categories were surveyed. Structured observation was used as data collection method and surveyed data was analysed using quantitative methods, namely classification tree analysis and the Fisher exact test supported by the log linear model. The results in the first instance indicated with very strong statistical significance that uniform/nonuniform brand transmutation is retail category specific. Secondly, at a five percent level of significance that the factors product characteristic tangibility/intangibility and uniform/non-uniform brand transmutation are dependent. Thirdly, at a one percent significance level, that different factor effects are of relative importance. The product characteristic tangibility/intangibility is the most important factor in offline/online brand element transmutation. Brand element transmutation is more important than the effect of the two factors. However, the factors and the effects are of high statistical significance and play a role in offline/online brand element uniformity/non-uniformity. The implication of this result is that products with tangible characteristics should be uniform offline and online, and commensurately products with intangible characteristics should be non-uniform offline and online. This may be explained by the inherent unsuitability of the Internet as distribution channel for tangible products and thus the risk reduction exercise in keeping the brand uniform offline/online.
\end{abstract}

The authors would like to thank Prof E vd M Smit for his valuable inputs in the statistical data analysis techniques.

*To whom all correspondence should be addressed.

\section{Introduction}

E-tailing is not for all products (Zhan \& Gery, 2000), and branding is not of equal importance to all online retail purchases. For example, research (Willcocks \& Plant, 2001:50-59) has indicated branding was of more importance than price in online fashion purchases. However, branding was not important in jewellery as well as home and garden purchases. The manufacturer's brand was also proved to be of more importance than the retailer's brand in the online purchase of furniture and appliances. It has also been stated that product characteristics and the suitability thereof to a virtual environment, influences the consumer's online shopping intention (Perea y Monsuwé, Dellaert \& De Ruyter, 2004:113). The former resulted in a comprehensive literature review on brand associations, brand element transmutation, offline/online product characteristics of brands and the inherent interactive and individualisation capabilities of the Internet, from which the research hypothesis was formulated. Previous research (Peterson, Balasubramanian \& Bronnenberg, 1997; Phau \& Poon, 2000; Vijayasarathy, 2002) has empirically proven that products with the following three characteristics namely one tangibility, two low cost, frequently purchased and three low differentiation potential, are not suited for Internet commerce. This study uses the former empirically validated construct of product characteristics and tries to find a correlation between the product characteristics and the uniformity/non-uniformity of the offline/online brand element transmutation. The aim of this study was to isolate at least one variable with statistical significance that explains offline/online brand element transmutation in the light of product characteristics of products sold online. The importance of variable isolation in this instance is to serve 
as indicator of an offline/online brand element transmutation strategy.

\section{Background}

The entities used to visually identify and differentiate a brand are called brand elements or brand identities (Keller, 2003:175). For the purposes of this paper the concept 'brand elements' will be used. Brand elements (brand names, logos, symbols, characters, packaging and slogans) are chosen to either enhance brand awareness or facilitate the formation of strong, favourable and unique brand associations (Aaker \& Joachimsthaler, 2000:xii, 351). A brand, signified by the brand elements, has multiple levels of meaning or association, recalled when the brand element is recognised. According to Rowley (2004:135) the brand elements help the buyer by '...conveying a bundle of attributes about the product or service'. The former provides value to the customer by enhancing the customer's confidence in the purchase decision, satisfaction of use as well as interpretation and processing of information. The brand elements thus become the metaphoric key for unlocking brand value or equity for the brand holder.

Contemporary brand equity is defined or conceptualised by three constructs based on academic research, namely customer psychology; economics; biology and sociology. The customer psychology approach uses behavioural models to define or conceptualise brand equity. The economics based approach defines or conceptualises brand equity in terms of the value ascribed to brands. The sociology and biology based approach defines or conceptualises brand equity by considering the broader cultural meaning of brands and products and services. For the purposes of this paper, the first approach, conceptualised by Aaker (1991; 1996; 1997:135-143; 2004a:36-39; 2004b:6-18), Aaker and Joachimsthaler (2000: xiii, 351) as well as Keller (1993:122 ; 1999:43-51; 2000:147-157; 2002:80-86) namely customer psychology, is used as it provides a conceptual framework that is most appropriate to study offline/online brand element transmutation because it differentiates dimensions of brand equity.

Aaker (1991:15-21) differentiates four dimensions of brand equity, namely brand awareness, brand associations, perceived quality and brand loyalty. Keller (2003:75-96) also differentiates four dimensions of what he calls 'customer-based brand equity': brand element (brand salience), brand meaning (brand performance and imagery), brand response (brand judgments and feelings) and brand relationships (brand resonance). In essence, the four dimensions differentiated by both Aaker (1991) and Keller (2003) are in content the same, though not in name. According to Chen (2001: 439), Aaker's (1991) 'brand associations' referred to as 'brand meaning' by Keller (2002), is the core asset of strong brand elements. He motivates this statement by explaining that brand awareness is necessary but not sufficient to build strong brand equity, perceived quality is a kind of brand association and that brand loyalty is the result of the amalgamation of the other dimensions of brand equity (Chen, 2001:439-440). Chen (2001:443) categorises brand associations as product or organisational associations. Product associations can be either functional or non-functional. Organisational associations can be either corporate ability associations or corporate social responsibility associations. Also see De Chernatony (2001:193) who refers to brand meaning as a cluster of functional and emotional associations. Low and Lamb $(2000: 351-353 ; 356)$ proved empirically that brand associations appear to consist of three distinct constructs (brand image, perceived quality and brand attitude) which measure different dimensions of brand associations. The dimension referred to by Low and Lamb (2000) as brand image consists of functional and symbolic beliefs that are product and service category specific and as such are the same as Chen's (2001) functional and non-functional product associations. It needs to be noted that Low and Lambs' (2000) brand association construct does not address organisational associations. For the purposes of this paper Chen's (2001) product brand association construct based on Aaker's (1991) brand equity construct, will be used as it more clearly elucidates the product brand association dimensions.

Aaker (Chen, 2001: 440) emphasised that the '...underlying value of a brand name [element] often is the set of associations - its meaning to people'. Collins (1977: 351) quotes Leduc as saying that the '...name [element] is the key to the product itself'. He proceeds to explain that the brand element '... reinforces the brand personality; enables the consumer to identify it; and is evidence that the manufacturer accepts responsibility for the quality of it'. A two part question can now be posited: firstly, will brand equity still be unlocked for the brand holder if this metaphoric key (the brand element) changes, and secondly, what is the role of the Internet in the transmutation or maintenance of the metaphoric key (the brand element)? (Collins, 1977:352)

According to Collins (1977:344) '...a change [transmutation] of name [element] represent upgrading of the thing named, but some name [element] changing is itself inspirational'. Kaikati and Kaikati (2003: 17) argue that '[r]obust brands have always had to evolve to remain desirable' and as such, justify changing the brand element. Research shows that some organisations use the Internet to reposition or evolve their brands, though not necessarily maintaining uniform brand elements in the process. Carpenter's (2000:109-152) case study of Barnes \& Noble/Barnesandnoble.com demonstrates how an online brand was created through the utilisation of the offline brand's credibility but presented in an amended format with the same - uniform - element. Offline brands should however be repositioned as quickly as possible otherwise they '....reflect a reluctance to build Internet opportunities'. (Rubinstein \& Griffiths, 2001:394-404).

Henderson and Cote (1998:14-30) as well as Gulati and Garino (2000:107-114) postulate that brand elements are either selected or changed after mergers and acquisitions; divestitures; new product, service and brand introductions; packaging changes; corporate image changes; major managerial or strategy shifts or image updates. Brand elements may also be changed because they do not translate across countries and cultures as the brand enters global markets (Rowley, 2004:134). Empirical research conducted 
by Check-Teck (2001:338) shows that complex brand elements are more attractive in the Singaporean technology market and as such validates the importance of brand resilience as the brand is expanded to global markets.

Robertson (1989:66) argues on the one hand that brand element transmutation is not justified if it '...would be easier to attain a desired image by building upon the base of existing, meaningful perceptions rather than starting with no such perceptual base' (see also Collins, 1977:352). However, the author argues on the other hand that a transmutated brand element without existing perceptions '...stand the best chance of not generating undesirable ones' (Robertson, 1989: 66; again see Collins, 1977:353 in this regard). Demonstrating the latter two arguments, Rowley (2004:131-138) sites the examples of tesco.com and CNN.com that transmutated online with uniform brands while other established offline brands chose 'unique and fresh elements', for example smile.co.uk. If an offering has high differentiation potential, the Internet can be an effective segmentation mechanism (Li \& Gery, 2000:51; Phau \& Poon, 2000:106-107). However, if a new offering is designed for a specific customer segment, the brand associations may become transmutated as the brand now has different associations for different segments, potentially resulting in brand equity proliferation (Rowley, 2004:134) In summary it can be said that a trade-off exists between leveraging the brand equity of the traditional offline brand in favour of the online brand, and a need to protect the brand equity of the traditional offline brand from erosion, as the brand enters a new marketplace and extended product and service offerings inevitably dilute the original brand associations and eventually the brand equity.

The strategic desirability of a brand element should thus be judged according to its ability to be encoded, retained and retrieved into, in and from memory (Robertson, 1989:62; 66; Henderson \& Cote, 1998:15) as well as the extent to which the brand element supports the desired brand image and strategic positioning of the product or service. An organisation will be wise to ask itself if the brand element was transmutated taking into considering the organisation's image; the direction the organisation is moving to and budgetary and other constraints (Henderson \& Cote, 1998:27). Collins (1977:354) points out that brand names are important in product categories where the difference between the nature and quality of competitive products are small (low differentiation potential) and where brand image is as a result of greater significance. The latter statement is confirmed by Low and Lamb (2000: 354) according to whom '...the broadest appropriate basis for conducting brand image [association] studies is product category'.

Kotler (2003: 410-411) classifies products according to product characteristics (durability; tangibility) and consumer shopping behaviour (use). Durability and tangibility are subdivided into three sub-classifications namely nondurable products (tangible and consumed after one or a few uses), durable products (tangible and not consumable after one or a few uses) and services (intangible, inseparable, variable and perishable products). Use is subdivided into two subclassifications called consumer products and industrial products. Consumer products are divided into four categories: convenience goods, shopping goods, speciality goods and unsought goods (see Kotler \& Armstrong, 2004: 280-281, as well as Murphy \& Enis, 1986: 25-29). Kotler's (2003) product classification construct which separates product characteristics and consumer shopping behaviour is used in this study due to its particular appropriateness in answering the posited research questions. Therefore, a strategy for maintaining or transmutating the associations of an existing offline brand, in and to an online brand, should therefore be based on an understanding of the product and service categorisation of the brand within the Internet environment.

The individualisation and interactive capabilities of the Internet has enabled organisations to '...configure products to meet individual customer needs' (Mohammed, Fisher, Jaworski \& Paddison, 2003:250). S.K. Chen (2001) examined inter alia the impact of the Internet on brands at a product level. Search and retrieval technologies are used to trace suppliers of particular products, allowing customers to compare prices and quality of products from different manufacturers. Personalisation capabilities enabled by cookies (bits of code that sit in a user's Web browser memory and identifies the user), collaborative filtering (software that resides on a Web site, that tracks the users' movements across Web sites and compares it with other visitors' behaviour), rule-based technology (uses business rules to segment users and to deliver profile-specific information), data mining tools and neural networks can track and record online website behaviour, increasing customisation based on user profiles. However, the Internet's current ability to reproduce only some sensory experiences (sight, sound, smell) limit the kind of products and services sellable on the Internet (Phau \& Poon, 2000: 103).

Mohammed et al. (2003: 492-493) states that the individualisation and interactive capabilities of the Internet has fundamentally changed branding - accelerating the brand experience. Individualisation makes it possible to customise the brand for a single individual (a market of one as opposed to a market of many) while giving the individual control over the nature and timing of interactions with the brand. Interactivity increases responsiveness and frequency of interaction as the individual can engage in immediate and direct dialogue with the brand, creating the expectation amongst customers that the brand will evolve according to their needs and desires. However, this shift of control of brand interaction from the brand to the customer which is the result of the Internet's individualisation and interactive capabilities may dilute the original or core brand associations (De Chernatony, 2001:186-195) as the brand's transmutation is now dictated by multiple markets-of-one.

Given the impact of the Internet's individualisation and interactive capabilities on products and brands, the first question that can be asked is what role the existing brand associations, represented by the brand element (name) ${ }^{1}$, play in the online environment. The purpose of the discussion in

\footnotetext{
${ }^{1}$ For the discussion in this paragraph, as in the rest of the paper, brand element (name) refers to the corporate brand element (name), unless stated otherwise.
} 
this paragraph is to substantiate the assumption that brand elements (names) are important in the online environment and not to argue whether such brand elements (names) are used for search - or experience products or services. The reason being that such a dichotomy is not as appropriate as the product and service characteristic categorisation conceptualised by Peterson et al. (1997:335) and used for the research reported in this paper. Ward and Lee (2000: 6) report that an Ernst \& Young survey indicated that 69 percent of the sample surveyed stated that the brand element (name) did indeed play a significant role in the online buying decision. Authors found evidence that suggests that on the Internet, brand elements (names) become substitutes for consumer's direct information search (Ward \& Lee, 2000:6). Phau and Poon (2000: 111) remark that '...Internet buyers will prefer well-known brands, as they are confident of the quality assurance'. Rubinstein and Griffiths (2001:394-404) also report that customers on the Internet will tend to choose brands they know. Known brands according to Bergstrom (2001: 11) represent '.... a set of values or attributes that are meaningful, clear, and trusted' and is therefore of particular importance in a virtual environment where the tangibility of the entity represented by the brand is very difficult to determine. Rowley (2004:133) substantiates this argument by pointing out that the brand element (name) plays an important role on the Internet as a keyword in the search process and that in order to reinforce brand familiarity, the domain name and the brand name should be linked and consistent. The author further remarks that evidence suggests that it is difficult to communicate an online brand in the absence of preconceptions relating to an offline brand (Rowley, 2004:33). Balabanis and Vassileiou (1999:378) say that '...retailers with strong brands are likely to benefit disproportionately from their brand's image effect on their web site's image compared to retailers with weaker brands'. Danaher, Wilson and Davis (2003: 474) also empirically confirmed that a strong brand (defined by the size of the market share) did better in an online environment compared to a weak brand. Research conducted by Kruger and Fourie (2003:27-34) indicated that 85.81 percent of online retail brands in South Africa, with pre-existing offline brands, maintained the uniformity of their brand elements when they transmutated online while 13.19 percent did not maintain the uniformity of their brand elements when they transmutated online. However, the research only described if brand elements of existing offline brands were uniformly or nonuniformly transmutated online, but did not empirically indicate if offline/online brand element transmutation was retail category specific and subsequently if transmutation (dependent or independent of the retail category) could be explained using the product and service characteristic classification conceptualised by Peterson et al. (1997).

The second question that can be asked is what role product and service characteristic categorisation plays in the online environment. Peterson et al. (1997:334) state that the '...suitability of the Internet for marketing to consumers depends to a large extent on the characteristics of the products and services being marketed'. Studies have also indicated that the Internet is sensitive to the nature of the products and services being marketed (Peterson et al., 1997:340; Phau \& Poon, 2000:105). The importance of product characteristic classification on the Internet is highlighted by Vijayasarathy $(2002: 413)$ who say that '...any discussion on the merits of the Internet as a commercial medium would be misleading if it fails to incorporate product differences and the concept of fit or congruence between product and channel characteristics'. The author motivates this statement by explaining that the benefits and limitations of the Internet as medium will be determined by the compatibility of Internet features and product and service characteristics, using the Internet as distribution, transaction or communication channel (Vijayasarathy 2002:422; see also Ward \& Lee, 2000:7). Traditional and virtual marketing activities occur through three types of channels: distribution channels, transaction channels and communication channels. The appropriateness of the Internet as distribution channel for products and services is determined by the physical characteristics of such products and services. This point is demonstrated by the Internet's suitability as distribution channel for digital commodities where delivery is instantaneous and variable costs are negligible as opposed to physical commodities where delivery is delayed and variable costs can be significant (Vijayasarathy, 2002:412). The assumption that sales will probably also vary by product category for both business-to-customer and business-to-business commerce (Bergstrom, 2000:11) verifies the need to develop a classification of product and service characteristics that will assist in evaluating the relationship between product and service characteristics and brands as they transmutate to the Internet. For comprehensive purposes it is mentioned that products and services can also be classified as search commodities (objective evaluation based on external information) or experience commodities (subjective evaluation based on personal use and application) - see Vijayasarathy (2002:415) and Ward and Lee (2000:8). However, although this type of product and service classification is not relevant for the purposes of this paper, it could be relevant to future research.

Different classifications, based on '...inherited, conferred, and perceived...' (Vijayasarathy, 2002: 415) product characteristics exist. The authors of this article agree with Rubinstein and Griffiths (2001: 394-404) and S. K. Chen (2001: 288-302) who stress the increasing importance of basing the relationship with the customer not on the brand's product alone, but also on the level of service associated with the brand, and as such refer to products as well as services in the course of this article. The classification system conceptualised by Peterson et al. (1997:335-336) categorises products and services along three dimensions namely cost and frequency of purchase, tangibility and degree of differentiation. The product and service characteristic classification conceptualised and empirically validated by Peterson et al. (1997), supported by Phau and Poon (2000) and Vijayasarathy (2002) is especially suitable to evaluate the appropriateness of brand association adjustment as reflected by the brand element transmutation according to products and services characteristic appropriateness on the Internet.

Low cost, frequently purchased commodities are usually consumable and need to be purchased regularly. High cost, infrequently purchased commodities are durable and are 
purchased irregularly. Tangible commodities are concrete while intangible commodities are service related and therefore abstract. A commodity has a high degree of differentiation if the seller is able to create a substantial competitive advantage through product and service differentiation as opposed to a low degree of differentiation applicable to generic products and services where it is not the case. Subsequently, based on empirical research conducted by Peterson et al. (1997), Phau and Poon (2000) and Vijayasarathy (2002) it can be said that the Internet is not a suitable distribution and transaction channel for low cost, frequently purchased, tangible offerings with a low differentiation potential. However, if the offering is intangible (travel, entertainment, financial), low cost and also needs to be frequently purchased, the Internet is a particularly suitable transaction and distribution channel.

In summary: brand associations are one of the dimensions of brand equity and the value of brand equity is unlocked by the brand element with its related associations; brand associations may be evaluated using product and service characteristics categorisations; the Internet with its individualisation and interactive capabilities has a profound impact on both products and services as well as brands; as such, products displaying certain product characteristics have been proven to be more or less suited for Internet commerce.

\section{Research questions}

Based on the above discussion, three research questions can now be posited:

1. Is the uniformity or non-uniformity of offline/online retail brand element transmutation in South Africa particular to certain retail product and service categories?

2. Are the product characteristics (tangibility/intangibility; high cost, low frequency/low cost, high frequency; high potential for differentiation/low potential for differentiation) of a product or service on the Internet and the transmutation of the product or services' brand elements (uniform/non-uniform) independent or dependent? Three hypotheses can be formulated in this regard:

$H t_{0}$ : The product characteristic (tangibility/intangibility) of a product or service on the Internet and the transmutation of the product or services' brand elements (uniform/non-uniform) are independent.

$H t_{l}$ : The two factors are dependent.

$H c_{0}$ : The product characteristic (high cost, low frequency/low cost, high frequency) of a product or service on the Internet and the transmutation of the product or services' brand elements (uniform/nonuniform) are independent.

$H c_{l}$ : The two factors are dependent.
$H d_{0}$ : The product characteristic (high potential for differentiation/low potential for differentiation) of a product or service on the Internet and the transmutation of the product or services' brand elements (uniform/non-uniform) are independent.

\section{$H d_{1}$ : The two factors are dependent.}

3. If certain product characteristics of a product on the Internet and the transmutation of the product's brand elements are dependent, what is the significance of the two factor effects?

$H_{0}: \lambda^{A B}=0$

The product's product characteristic (tangibility/intangibility; high cost, low frequency/low cost, high frequency; high potential for differentiation/low potential for differentiation) on the Internet and the transmutation (uniform/non-uniform) of the product's brand elements are independent and therefore not of relative significance.

$H_{1}: \lambda^{A B} \neq 0$

The two factors are dependent and therefore of relative significance.

\section{Research methodology}

A deductive research approach is followed and the research strategy identified as appropriate to answer the research questions is a survey strategy using structured observation as data collection method. Data is analysed using quantitative methods, namely classification tree analysis, Fisher's exact test supported by the log linear model.

The authors used the list of South African offline/online retailers as per 'The Goldstuck Report: Online Retail in South Africa, 2002' (Goldstuck, 2002: 1-36) to build a database of offline/online retail brand element transmutation in South Africa. Through a research process regarded by the Goldstuck Report (Goldstuck, 2002) as preliminary, a sample of 215 offline/online retailers was identified from the ever expanding online retail population. The online retailers in the sample had to meet two criteria to be included namely, a transaction mechanism and product lines that had to meet the traditional understanding of retail products as per the definition of Statistics South Africa. The result was a list of 215 online/offline retailers divided into 17 categories: adult; apparel; appliances; arts, crafts and collectables; books, magazines and stationary; electronics; flowers and gifts; food and beverage; general; health and beauty; home and garden; jewellery; lingerie; music; sports and recreation; toys and hobbies; wine. The adult offline/online retail category with four offline/online retailers was excluded due to ethical reasons. The remaining 211 offline/online retailers divided into 16 retail categories were examined in two stages.

The brand element of the offline brand was compared with the brand element of the online brand, thus supposing that both an offline and online brand existed with brand elements to be compared and subsequently recorded. If the brand elements were uniform (the same) offline as well as online, 
a 'yes' answer was recorded and if not, a 'no' answer. This process of observation is however limited as it only allows for binary observations and as such does not accommodate the possibility of neither 'yes' nor 'no' that will be applicable in the case where the online brand element is an extension of the offline brand element. In this instance, a 'no' answer was recorded. The 'yes' and 'no' observations for each of the 16 retail categories were amalgamated. In order to answer the first research question ('Is the uniformity or non-uniformity of offline/online retail brand element transmutation in South Africa particular to certain retail product categories?') a quantitative data analysis method called classification tree analysis was used to analyse the observed surveyed data. A short description of this methodology follows below.

\section{Classification tree analysis methodology}

In the case of classification trees the dependent variable $y$ is a discrete variable consisting of two or more classes (e.g. yes/no, low/medium/high). The concept of entropy (chaos) is used as basis for constructing classification trees. To explain entropy in the framework of classification trees, consider a dependent or response variable with two classes namely yes/no. If a data set consists of $50 \%$ yes and $50 \%$ no responses, then the entropy of that data set is a maximum because the data will have only a $50 \%$ chance of correctly predicting the class of the dependent variable. As the proportion of one of the classes tends to $100 \%$, the lower the entropy becomes, and it reaches a minimum when a data set consists of $100 \%$ of one class. In this case the data will have a $100 \%$ chance of correctly predicting the class of the response variable. The aim of a classification tree is to divide the data set into subsets such that the subsets have lower entropy than the full data set. It therefore strives to group the classes together into subsets as best possible based on the independent or predictor variables. Different methods can be followed to achieve minimum entropy levels, depending on the properties (continuous, categorical) and number of the independent variable(s). In this instance there is one independent variable and it is of a categorical nature. The dependent variable has two classes namely 'yes' (which means the online and offline brand is uniform) and 'no' (which means the online and offline brands is not uniform or transmutated).

The product characteristics categorisation of Peterson et al. (1997:335-336), also used by Phau and Poon (2000: 103) and Vijayasarathy (2002: 412) for empirical research, was used to record the product characteristics of the online product offerings of 89 offline/online retailers (portion of 211 offline/online retailers with existing and traceable offline/online brands). If the offline and online product offering was tangible a 'yes' answer was recorded and if not, a 'no' answer. If the cost was high (and by implication the purchase frequency low) 'high' was recorded and if the cost was low (and by implication the purchase frequency high) 'low' was recorded. A product was recorded as 'high' cost if its purchase price was above ZAR 3000,00 and as 'low' cost if it was below this amount. If the differentiation potential was high, 'high' was recorded and if low, 'low' was recorded. As in stage one, it was a prerequisite that the brands surveyed should be offline, transmutated (uniform or non-uniform) online. This process of observation is however limited as it only allows for binary observations and as such does not accommodate the possibility of neither 'high' nor 'low' that will be applicable in the case where the product of the online brand has neither high nor low differentiation potential or is neither high nor low in cost and commensurately in frequency of purchase. The 'yes'/'no' and 'high'/'low' observations for the products of each of the 16 retail categories were amalgamated to answer the second and third research questions. Fisher's exact test as primary method, supported by the log linear model as secondary method (Steyn, Smit \& Du Toit, 1989: 461-472) were used as discriminant function analysis techniques to analyse the interaction between the factors (product characteristic and brand transmutation) of an observed two way contingency table. A short description of the methodologies of Fisher's exact test and the log linear model follows below.

\section{Fisher's exact test and the log linear model methodology}

Table 1: Observed frequencies for product characteristics and brand transmutation

\begin{tabular}{l|c|c}
\hline & \multicolumn{2}{c}{ Brand transmutation } \\
\hline Product characteristics & Yes & No \\
\hline Tangible & 74 & 7 \\
\hline Yes & 5 & 3 \\
\hline No & \multicolumn{2}{|}{} \\
\hline Cost and frequency & 28 & 2 \\
\hline High and low & 51 & 8 \\
\hline Low and high & 73 & 10 \\
\hline Differentiation potential & 6 & 0 \\
\hline High &
\end{tabular}

The Fisher exact test is firstly used as primary method to analyse the data because it allows an exact probability to be calculated for small $n$ and secondly because sparse cells in the table may render the log linear analysis unreliable.

\section{Fisher's exact test}

The Fisher exact test is a small-sample test of independence (Agresti, 2002:91) that is only available for $2 \times 2$ tables. For $2 \times 2$ tables independence is equivalent to the odds ratio $\theta=$ 1 .

Test statistic

To test $H_{0}: \theta=1$, the $p$ value is the sum of certain hypergeometric probabilities. The underlying rationale of the test is to exactly compute the probability of obtaining cell frequencies as uneven as (or more uneven than) observed frequencies for small $n$ by counting all possible tables that can be constructed based on the marginal frequencies. The calculated statistics therefore enable the evaluation of the relationship between two dichotomous variables. A data analysis software system, STATISTICA 7, is used to compute Fisher's exact test for the research reported in this paper.

\section{Distribution}

The exact test for $2 \times 2$ tables utilises the hypergeometric distribution to calculate one-tailed $p$-values. 
Hypothesis

$H_{0}$ : Row (brand transmutation) and column (product characteristics) factors independent

$H_{l}$ : Row (brand transmutation) and column (product characteristics) factors dependent

Decision rule

Accept $H_{0}$ if $p \geq 0,05$ (row and column factors independent) Accept $H_{1}$ if $p<0,05$ (row and column factors dependent)

\section{The log linear model}

\section{Step one: the $(2 \times 2)$ independence test}

If $n$ entities are simultaneously classified according to the occurrence or not of two attributes, the $(2 \times 2)$ independence test is used to determine if there is dependence or interaction between the attributes.

Test statistic

If

Wij is the $(i j)^{\text {th }}$ observed frequency; $i=1,2 ; j=1,2$

$\mathrm{R} i$ the $i^{\text {th }}$ row total

$\mathrm{C} j$ the $j^{\text {th }}$ column total

$n$ the sample size

Then

test statistic $Y=\frac{\mathrm{n}\left(\left|\mathrm{W}_{11} \mathrm{~W}_{22}-\mathrm{W}_{12} \mathrm{~W}_{21}\right|-\mathrm{n} / 2\right)^{2}}{\mathrm{R}_{1} \mathrm{R}_{2} \mathrm{C}_{1} \mathrm{C}_{2}}$

Distribution

The test statistic $\mathrm{Y}$ has an approximated $X^{2}(1)$ distribution if $n$ is large $(n>5)$ enough and $R_{i} C_{j} / n \geq 5$ for all $i$ and $j$

Hypothesis

$H_{0}$ : Row (brand transmutation) and column (product characteristics) factors independent

$H_{1}$ : Row (brand transmutation) and column (product characteristics) factors dependent

Decision rule

Accept $H_{0}$ if $\mathrm{y}<X_{1 ; \alpha}^{2}$ (row and column factors independent) Accept $H_{l}$ if $\mathrm{y} \geq X^{2}{ }_{1 ; \alpha}$ (row and column factors dependent)

where

$$
\alpha=0,05 \text { (a five percent level of significance) }
$$

\section{Step two: determining the appropriate model}

If a random sample with $n$ entities is taken from a population and classified according to two factors (in this instance brand transmutation and product characteristics, each with two possible outcomes), it results in an observed (2x2) frequency table. Similarly, an expected $(2 \times 2)$ frequency table can be compiled by replacing observed frequencies with expected frequencies. If $\pi i j$ is the probability for an observation to fall in the $(i j)^{\text {th }}$ cell of the (2x2) frequency table, the corresponding expected frequency $\mathrm{V} i j=n \pi i j$. The log linear model is based on $\zeta_{\mathrm{ij}}=\ln (v i j) ; i=$ 1,$2 ; j=1,2$ where "In" indicates the natural logarithmic $\log _{\mathrm{e}}$. This linear representation of logarithms of expected frequencies is called the two-way log linear model. The row $\left(\lambda^{\mathrm{A}}{ }_{\mathrm{i}}, \mathrm{i}=1,2\right)$ and column $\left(\lambda_{\mathrm{B}}^{\mathrm{B}}, j=1,2\right)$ effects are called main effects. The effects between a specific row and column $\left(\lambda^{\mathrm{AB}}{ }_{\mathrm{ij}}, i=1,2 ; j=1,2\right)$ is called first order interaction effects. The unknown $\mu$ together with the $\lambda \mathrm{s}$ is called the parameters of the model. From the linear relationship between subjacent main effects and subjacent interaction effects it follows that only one $(I-1)$ row effect, one $(J-1)$ column effect and one $\{(I-1)(J-1)\}$ interaction effect are unknown. The model therefore contains unknown parameters. As the model has an equal amount of unknown parameters and cells in the contingency table, the model is referred to as the satisfied model. If no interaction exists between the row and column factors, it means that all the $\lambda^{\mathrm{AB}}{ }_{\mathrm{ij}}$ - effects are equal to 0 . In this instance the model is referred to as the independence model.

Test statistic

$L=2 \Sigma_{i=1}^{2} \Sigma_{j=1}^{2} W_{i j} \ln \left(\mathrm{W}_{i j} / \mathrm{V}_{i j}\right)$ with $V_{i j}=n \pi i j$

Distribution under $H_{0}$

The test statistic $L$ has an approximated $X^{2}\{(I-1)(J-1)\}$, i.e. $X^{2}(1)$ distribution

Hypothesis

$H_{0}: \lambda^{A B}=0$ (independence model)

$H_{1}: \lambda^{A B} \neq 0$ (satisfied model)

Decision rule

Accept $H_{0}$ if $l^{*}<X^{2} 1 ; \alpha$

Accept $H_{l}$ if $l^{*} \geq X^{2} 1 ; \alpha$

where

$\alpha=0,05$ ( $\alpha$ five percent level of significance)

$l^{*}$ is used as the observed value of $L$ to eliminate later confusion

Step three: calculating the parameters of the appropriate model

Once it has been determined which of the existing models (satisfied or independence) fit the observed frequency table best the parameters of the appropriate model are calculated. Once the parameters have been calculated, the significance of the parameters is determined.

Parameter calculation for satisfied model

$Z i j=\ln (w i j)$

Parameter calculation for independence model $Z i j=\ln (v i j)$

Test statistic and distribution

In order to determine if any of the calculated parameters represent a significant effect, the Goodman result is used: If $l$ is an estimation of $\lambda$, one of the unknown parameters in the $\log$ linear representation of the $(2 \times 2)$ contingency table and $\mathrm{s}_{l}$ is the standard deviation of $l$, then the test statistic

$(l-\lambda) / \mathrm{s}_{l}$

Has an approximate $n(0 ; 1)$ population. 
Decision rule

To determine if an effect is significant or not, the following rule is used:

$l$ not significant $(\lambda=0)$ if $\left|l / s_{l}\right|<\alpha$

$l$ significant $(\lambda \neq 0)$ if $\left|l / s_{l}\right| \geq \alpha$, where $\alpha=0,01$ (a one percent level of significance)

\section{Results}

Application of the classification tree analysis showed that the 15 categories could successfully be separated into three distinct groups, each with different entropy levels.

\section{1/59\% Category classification}

RETAIL CATEGORY AND NODE: Arts, Crafts \& Collectables; General; Home \& Beauty

Categorised Histogram NODE X UNIFORM

Chi-square test $p=.00009$

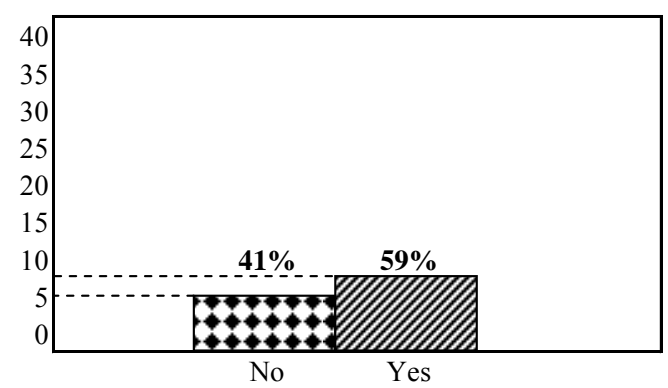

Figure 1: Arts, crafts and collectables; general; home and beauty

\section{1/89\% Category classification}

RETAIL CATEGORY AND NODE: Apparel; Books, Magazines \& Stationary; Food \& Beverages

Categorised Histogram: NODE X UNIFORM

Chi-square test: $p=.00009$

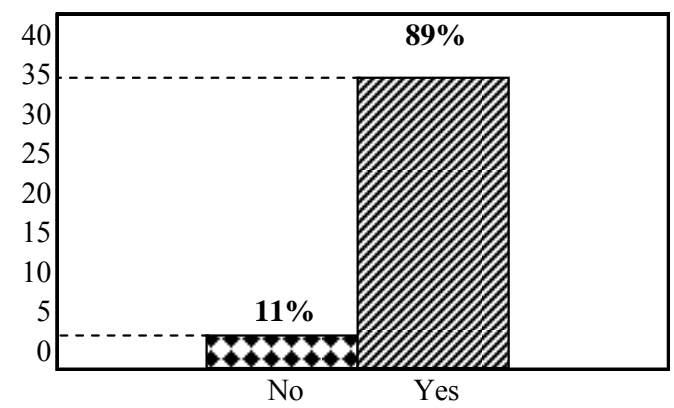

Figure 2: Apparel; books, magazines and stationary; food and beverages

\section{0/100\% Category classification}

RETAIL CATEGORY AND NODE: Appliances; Electronics; Flowers \& Gifts; House \& Garden; Jewellery; Lingerie; Music; Sports \& Recreation; Toys \& Hobbies; Wine

Categorised Histogram: NODE X UNIFORM

Chi-square test: $p=.00009$

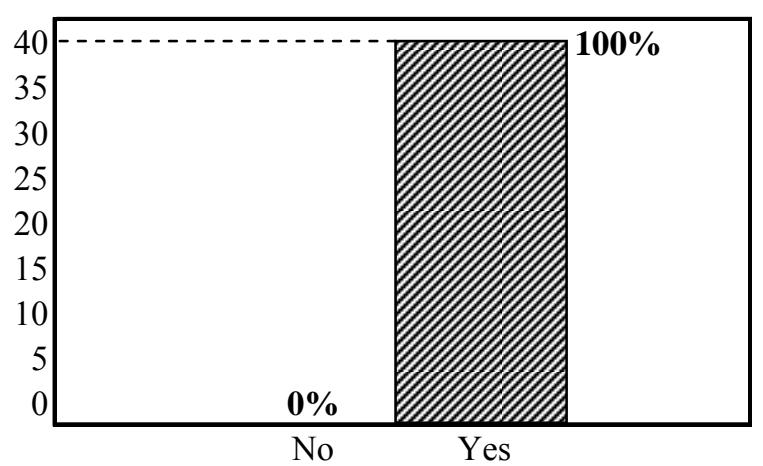

Figure 3: Appliances; electronics; flowers and gifts; house and garden; jewellery; lingerie; music; sports and recreation; toys and hobbies; wines

\section{Fisher's exact test for (2x2) tables}

Product characteristic tangibility/intangibility and uniform/non-uniform brand

Step one

$H t_{0}$ : The product characteristic (tangibility/intangibility) of a product or service on the Internet and the transmutation of the product or services' brand (uniform/non-uniform) are independent.

$H t_{l}$ : The two factors are dependent.

Step two

The null hypothesis $\left(H t_{0}\right)$ will be accepted if $p \geq 0,05$ and the alternative hypothesis $\left(H t_{l}\right)$ will be accepted if $p<0,05$.

Step three

The $p$-value $=0,04305$

Step four

As the $p$-value $<0,05$ the alternative hypothesis $\left(H t_{l}\right)$ is accepted at a five percent significance level.

Product characteristic high cost, low frequency/low cost, high frequency and uniform/non-uniform brand

Step one

$H c_{0}$ : The product characteristic (high cost, low frequency/low cost, high frequency) of a product or service on the Internet and the transmutation of the product or services' brand (uniform/non-uniform) are independent.

$H c_{l}$ : The two factors are dependent. 
Step two

The null hypothesis $\left(H c_{0}\right)$ will be accepted if $p \geq 0,05$ and the alternative hypothesis $\left(H c_{1}\right)$ will be accepted if $p<0,05$.

Step three

The $p$-value $=0,27618$

Step four

As the $p$-value $>0,05$ the null hypothesis $\left(H c_{0}\right)$ is accepted.

Categorised Histogram: TANGIBLE X UNIFORM Chi-square test: $=.03786$ Fischer exact, one-tailed $p=.04305$

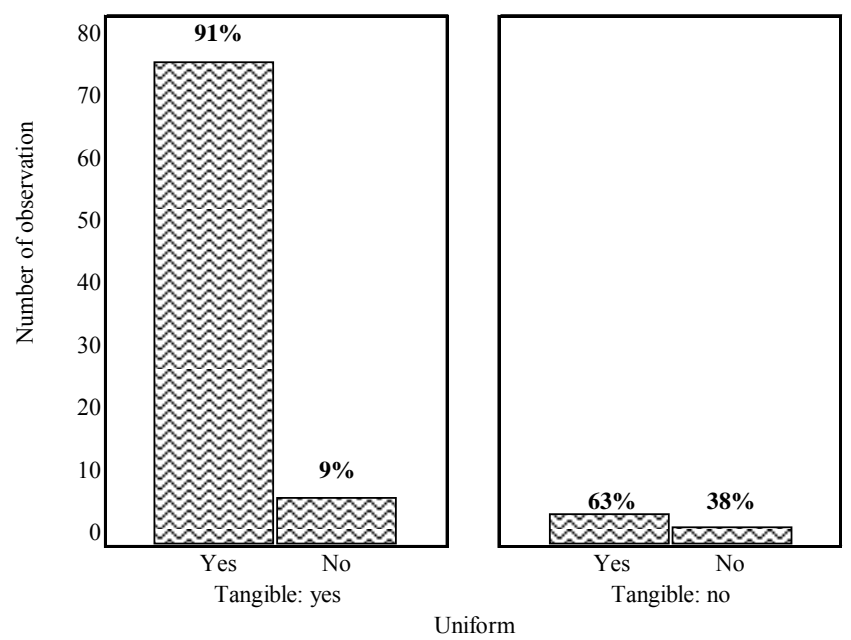

Figure 4: Product characteristic tangibility/intangibility and uniform/non-uniform brand transmutation

Categorised Histogram: COST \& FREQUENCY X UNIFORM Chi-square test: $=.31137$ Fischer exact, one-tailed $p=.27618$

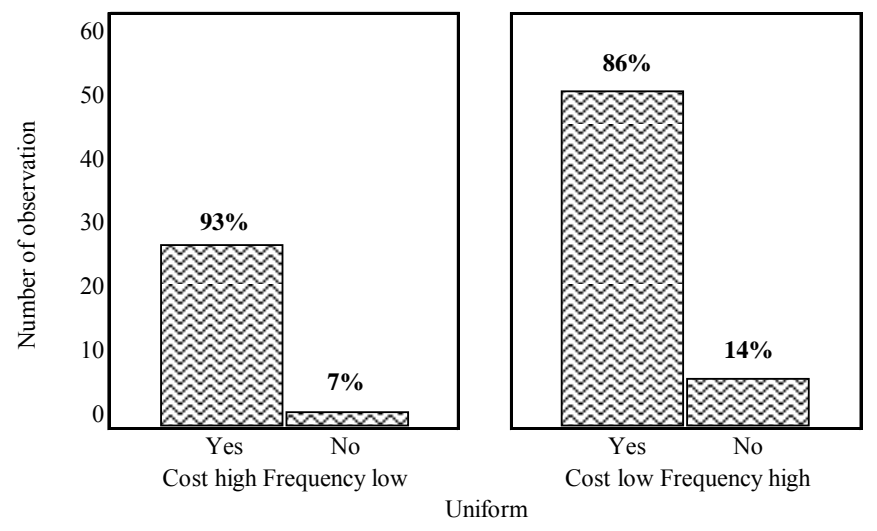

Figure 5: Product characteristic high cost, low frequency/low cost, high frequency and uniform/nonuniform brand transmutation

Product characteristic high potential for differentiation/low potential for differentiation and uniform/non-uniform brand

Step one

$H d_{0}$ : The product characteristic (high potential for differentiation/low potential for differentiation) of a product or service on the Internet and the transmutation of the product or services' brand (uniform/nonuniform) is independent.

$\mathrm{Hd}_{l}$ : The two factors are dependent.

Step two

The null hypothesis $\left(H d_{0}\right)$ will be accepted if $p \geq 0,05$ and the alternative hypothesis $\left(H d_{1}\right)$ will be accepted if $p<0,05$.

Step three

The $p$-value $=0,47833$

Step four

As the $p$-value $>0,05$ the null hypothesis $\left(H d_{0}\right)$ is accepted.

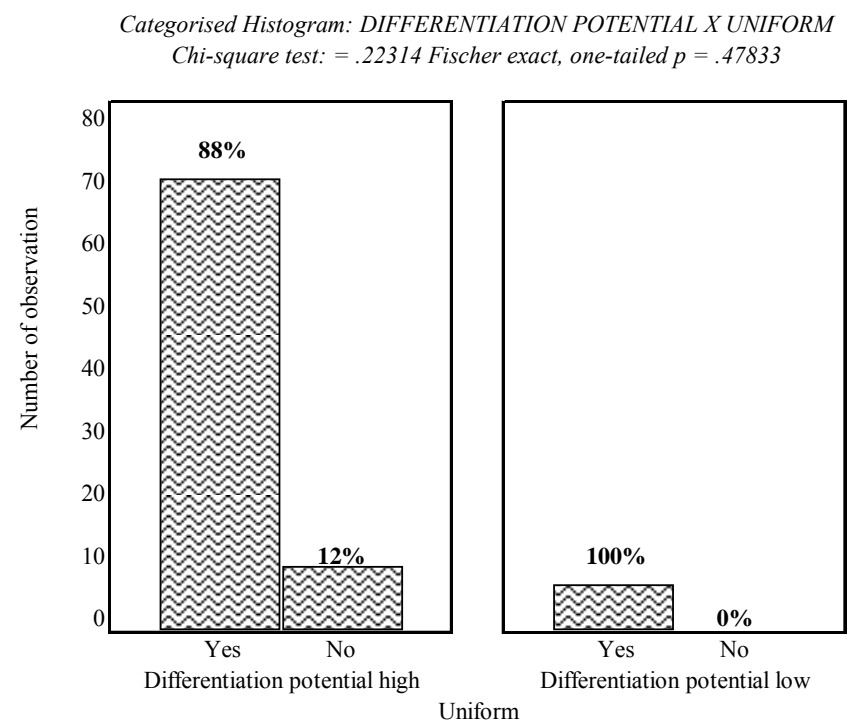

Figure 6: Product characteristic high potential for differentiation/low potential for differentiation and uniform/non-uniform brand transmutation

As a valuable check on the results produced by Fisher's exact test, log linear analyses were also performed on the data under exactly the same hypotheses to confirm and further analyse the results obtained through Fisher's exact test.

\section{Log linear model}

Product characteristic tangibility/intangibility and uniform/non-uniform brand

\section{Step one}

$H t_{0}$ : The product characteristic (tangibility/intangibility) of a product or service on the Internet and the transmutation of the product or services' brand (uniform/non-uniform) are independent.

$H t_{l}$ : The two factors are dependent.

Step two

$X_{1 ; 0,05}^{2}=3,842$, therefore the alternative hypothesis $\left(H t_{1}\right)$ will be accepted if test statistic $y \geq 3,842$, the null hypothesis $\left(H t_{0}\right)$ will be accepted if $y<3,842$

Step three

The test statistic $y=6,628$ 
Step four

As $y \geq 3,842$ the alternative hypothesis $\left(H t_{l}\right)$ is accepted at a five percent significance level.

Product characteristic high cost, low frequency/low cost, high frequency and uniform/non-uniform brand

Step one

$H c_{0}$ : The product characteristic (high cost, low frequency/low cost, high frequency) of a product or service on the Internet and the transmutation of the product or services' brand (uniform/non-uniform) are independent.

$H c_{l}$ : The two factors are dependent.

\section{Step two}

$X_{1 ; 0,05}^{2}=3,842$, therefore the alternative hypothesis $\left(H c_{1}\right)$ will be accepted if test statistic $y \geq 3,842$, the null hypothesis $\left(H c_{0}\right)$ will be accepted if $y<3,842$

Step three

The test statistic $y=1,284$

Step four

As $y<3,842$ the null hypothesis $\left(H c_{0}\right)$ is accepted.

Product characteristic high potential for differentiation/low potential for differentiation and uniform/non-uniform brand

Step one

$H d_{0}$ : The product characteristic (high potential for differentiation/low potential for differentiation) of a product or service on the Internet and the transmutation of the product or services' brand (uniform/non-uniform) is independent.

$H d_{l}$ : The two factors are dependent.

Step two

$X_{1 ; 0,05}^{2}=3,842$, therefore the alternative hypothesis $\left(H d_{1}\right)$ will be accepted if test statistic $y \geq 3,842$, the null hypothesis $\left(H d_{0}\right)$ will be accepted if $y<3,842$

Step three

The test statistic $y=2,470$

Step four

As $y<3,842$ the null hypothesis $\left(H d_{0}\right)$ is accepted.

\section{Model determination: satisfied or independence}

Step one

Hypotheses

$H_{0}: \lambda^{A B}=0$ (independence model)

$H_{1}: \lambda^{A B} \neq 0$ (satisfied model)

Step two

$\alpha=0,01$ therefore the alternative hypothesis will be accepted if $\left|l^{*}\right| \geq 2,58$

Step three

Calculated test value

$l^{*}=6,816$
Step four

As $\left|l^{*}\right| \geq 6,635$ the alternative hypothesis $\left(H_{l}\right)$ is accepted at a one percent level of significance and therefore the satisfied model will be used to display the observed $(2 \times 2)$ contingency table.

\section{Determining parameters of appropriate model}

Table 2: Estimated $\lambda$-effects, standard deviations of $\boldsymbol{l}$ estimations and standardised $l$-values for the log linear analysis of the satisfied model

\begin{tabular}{c|c|c|c}
\hline Effect & $\boldsymbol{l}$ & $\boldsymbol{l} / \boldsymbol{s}_{\boldsymbol{l}}$ & Meaningful? \\
\hline$\lambda^{A}{ }_{1}$ & 0,0645325 & 3,31489 & Yes \\
\hline$\lambda^{A}{ }_{2}$ & $-0,0645325$ & $-3,31489$ & Yes \\
\hline$\lambda^{B}{ }_{1}$ & 0,813575 & 4,17916 & Yes \\
\hline$\lambda^{B}{ }_{2}$ & $-0,813575$ & $-4,17916$ & Yes \\
\hline$\lambda^{A B}{ }_{11}$ & 0,533775 & 2,74188 & Yes \\
\hline$\lambda^{A B}{ }_{12}$ & $-0,533775$ & $-2,74188$ & Yes \\
\hline$\lambda^{A B}{ }_{21}$ & $-0,533775$ & $-2,74188$ & Yes \\
\hline$\lambda^{A B}{ }_{22}$ & 0,533775 & 2,74188 & Yes \\
\hline
\end{tabular}

$\mathrm{s}_{l}=0,1946745$

\section{Discussion}

The first research question can be answered positively: uniformity or non-uniformity of offline/online retail brand element transmutation in South Africa seems to be particular to certain retail product categories. Three of the retail categories (Arts, Crafts and Collectables; General; Home and Beauty) could successfully be placed in the $41 / 59 \%$ classification (with high statistical significance). For these categories the entropy is near maximum which means it is very difficult to predict whether the online/offline retail brand names in any of these categories would be uniform or not as the distribution between uniformity and nonuniformity was very even. It also does not appear to matter whether the brand name was well known or less well-known as less well-known online/offline retail brand names appear to be uniform and non-uniform in near equal proportions. Three of the categories (Apparel; Books, Magazines and Stationary; Food and Beverages) could successfully be placed in the $11 / 89 \%$ classification (with high statistical significance). The entropy is at a very low level in these categories which means online/offline brand name uniformity can be predicted fairly confidently. The majority of well-known offline brand names have uniform online brand names. The remaining ten categories Appliance; Electronics; Flowers and Gifts; House and Garden; Jewellery; Lingerie; Music; Sports and Recreation; Toys and Hobbies, Wine could all be placed in the $0 / 100 \%$ classification. The entropy is at a minimum and 
online/offline brand name uniformity can be predicted with certainty. Well-known as well as less well-known brands have uniform online/offline brand names. There is a pronounced profile of brand uniformity being category dependant.

The second research question can be answered as follows. The first alternative hypothesis $\left(H t_{l}\right)$ is significant at a five percent significance level. This means that there seems to be significant dependence between the factors tangibility/intangibility of product characteristic and the uniformity/non-uniformity of the brand transmutation. The finding implies that the tangibility/intangibility of a product influences whether the brand element will be uniformly/nonuniformly transmutated on the Internet and commensurately, that the uniformity/non-uniformity of the offline/online brand elements is influenced by the tangibility/intangibility of its product. The second and third alternative hypotheses ( $H_{c l}$ and $H_{d l}$ respectively) are rejected as they are not significant at a five percent level. This means that although there may be some dependency between the product characteristics (high cost, low frequency/low cost, high frequency and high potential for differentiation/low potential for differentiation) and the uniformity/nonuniformity of offline/online brand element transmutation, it can not be regarded as significant on a statistical basis. Therefore, the product characteristics high cost, low frequency/low cost, high frequency and high potential for differentiation/low potential for differentiation do not influence the uniformity/non-uniformity of the brand transmutation.

The second research question established dependence between the factors tangibility/intangibility of the product characteristic and the uniformity/non-uniformity of its offline/online brand transmutation. Subsequently, to answer the third research question, it was firstly established that a satisfied model was most appropriate to the observed frequency table at a one percent level of significance (a stronger significance level than usual - one percent - is used as the log linear model uses approximations and it aims to prove that a relationship is truly significant if it appears significant). Secondly, all the parameters of the satisfied model were determined. The standardised values $\left(l / s_{l}\right)$ of all the approximations in Table One above indicate that the product characteristic tangibility/intangibility is the most important effect, while uniform/non-uniform brand transmutation is the less important effect and tangibility/uniformity; tangibility/non-uniformity; intangibility/uniformity; intangibility/non-uniformity the least important effect. The positive sign of $l^{A}{ }_{1}$ in contrast to the negative sign of $l^{A}{ }_{2}$ is an indication that on the Internet more offline brands are uniform than non-uniform. Likewise the positive sign of $l_{1}^{B}$ and negative sign of $l^{B}{ }_{2}$ indicate that on the Internet more products are tangible than intangible. More uniform brands have tangible product offerings than intangible product offerings as indicated by the positive sign of $l^{A B}{ }_{11}$ and the negative sign of $l^{A B}{ }_{12}$. Similarly, more nonuniform brands have intangible product offerings than tangible product offerings as demonstrated by the negative sign of $l^{A B}{ }_{21}$ and the positive sign of $l^{A B}{ }_{22}$. Hypothesis testing indicated that all the different effects were significant at a one percent level of significance. Figure seven below demonstrates the relative importance between the factors.

\section{Conclusion and managerial implications}

The implications of the first research question will only be discussed after the second and third research questions for elucidatory purposes. In the light of the above results in can be stated that it seems as if brand elements are transmutated uniformly if the product offering is tangible and nonuniformly if the product offering is intangible. This supposition is specifically supported by the fact that more uniform brands have tangible product offerings than intangible product offerings and more non-uniform brands have intangible product offerings than tangible product offerings. The former supposition is further validated by the implication of the results of the first research question. In the $41 / 59 \%$ category it is very difficult to predict if a brand in one of the retail categories will be uniformly or nonuniformly transmutated online. This may be explained by the fact that one of the retail categories namely 'General' include more brands with non-tangible product offerings transmutated non-uniformly online compared to the singular brands with intangible product offerings also transmutated non-uniformly online, that is part of the retail category 'Books, Magazines and Stationary', one of the retailers in the $11 / 89 \%$ category. In the $0 / 100 \%$ category uniformity can be predicted with high certainty and this may be explained by the fact that none of the brands were intangible and subsequently non-uniformly transmutated online. The implications of the results of the classification tree analysis explained in the light of the results of the log linear analysis therefore support the statement that keeping brand elements uniform for tangible products and non-uniform for intangible products means that the metaphoric key unlocking brand equity stays the same for tangible products, but not for intangible products. The existing dimensions of the offline brand's equity (brand awareness, brand associations, perceived quality, and brand loyalty) can therefore be leveraged in favour of the online brand in the first instance, but not in the latter instance. Brand associations therefore by implication stay the same if the offline/online brand's elements are uniform, but do not stay the same if the offline/online brand's elements are nonuniform. This situation seems to be particular to tangible/intangible product characteristics. It can therefore firstly be postulated that the product characteristic tangibility/intangibility also determines if an offline/online brand should be uniform/non-uniform. The role the inherent capabilities of the Internet play in this instance may be explained by the Internet's suitability or not as distribution, marketing and transaction channel for tangible/intangible products respectively. Secondly, it can be postulated that if the Internet is unsuitable as a distribution and transaction channel because of the brand's product characteristic - for example tangibility - then it is probably used as a communication channel, explaining a uniform offline/online brand element strategy. On the other hand, if the Internet is suitable as a distribution, transaction and communication channel because of the brand's product characteristic - for example intangibility - then it is probably fully utilised as such, explaining a non-uniform offline/online brand element strategy. 


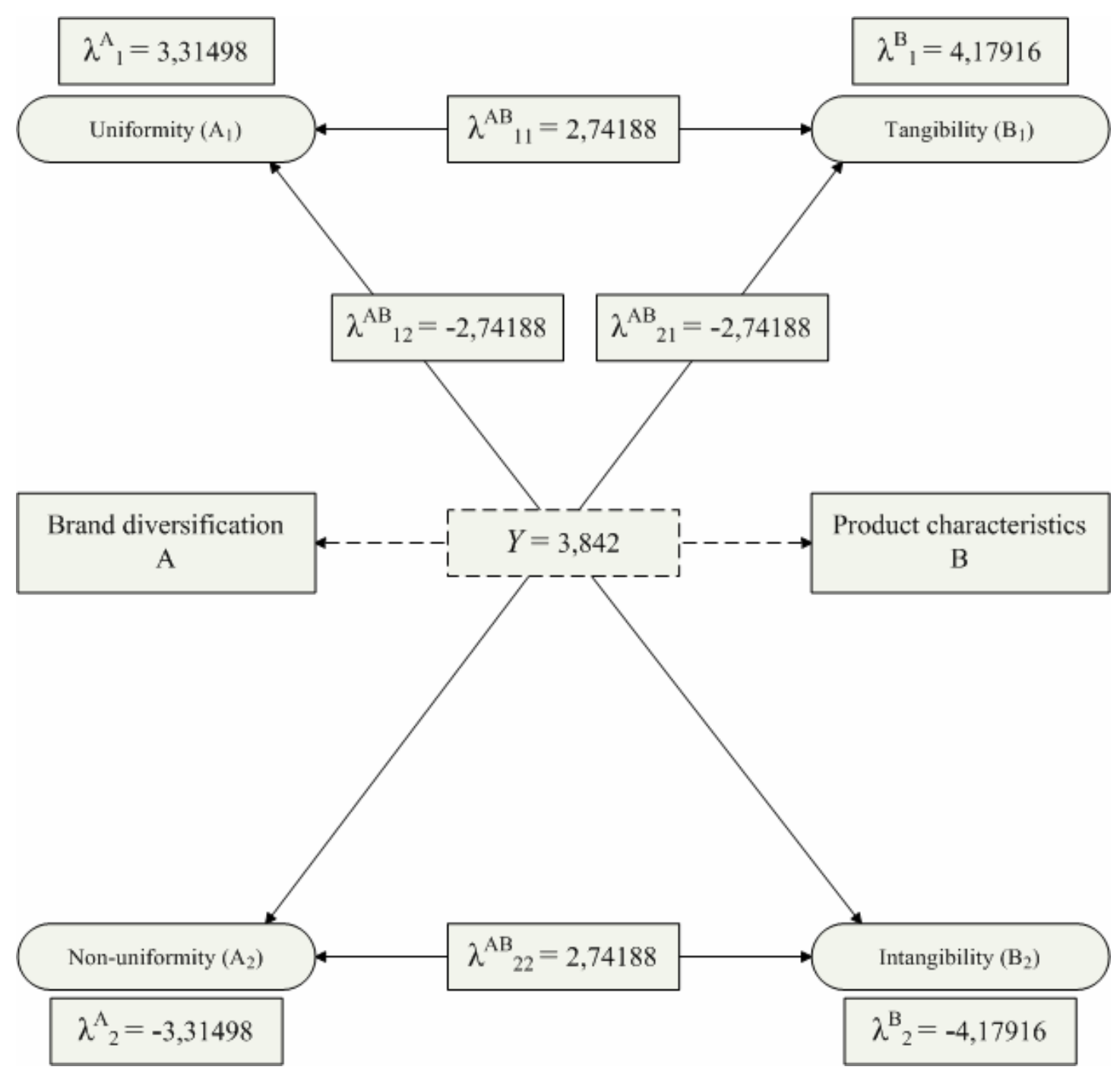

Figure 7 Data network displaying relative factor (brand transmutation and product characteristics) values of the satisfied log linear model

\section{Limitations and suggestions for future research}

Limitations to the study include a small population and binary observations of product characteristics. Future research should investigate the relationship between the retail category taxonomy as the result of classification tree analysis and the product characteristic tangibility/intangibility and uniform/non-uniform brand transmutation of offline/online brands. Future research could also address the particularity and appropriateness of value propositions (functional, emotional, and self-expressive) in respect of offline/online brand element transmutation. Scientifically researching the connection between existing marketing channels (distribution, communication, and transaction) and offline/online brand element transmutation will also prove to answer some questions around the transmutation of offline/online brand elements. The link between search - and experience products, in other words online customer behaviour, and online/offline brand transmutation, as alternative point of departure for a study, may also possibly divulge variables that play a role in branding on the Internet.

\section{References}

Aaker, D. A. 1991. Managing brand equity: Capitalizing on the value of a brand name. New York: The Free Press.

Aaker, D. A. 1996. Building strong brands. New York: The Free Press.

Aaker, D. A. 1997. ' Should you take your brand to where the action is?' Harvard Business Review, 75(5):135-143.

Aaker, D. A. 2004a. 'Even brands need spring cleaning', Brandweek, 45(10): 36-39.

Aaker, D. A. 2004b. 'Leveraging the corporate brand', California Management Review, 46(3):6-18.

Aaker, D. A. \& Joachimsthaler, E. 2000. Brand leadership. New York: The Free Press.

Agresti, A. 2002. Categorical data analysis. 2nd Edition. New Jersey: John Wiley \& Sons, Inc. 
Balabanis, G., \& Vassileiou, S. 1999. 'Some attitudinal predictors of home-shopping through the Internet', Journal of Marketing Management, 15(5):361-385.

Bergstrom, A. 2000. 'Cyberbranding: Leveraging your brand on the Internet', Strategy \& Leadership, 28(4):10-15.

Carpenter, P. 2000. eBrands: building an Internet business at breakneck speed. Boston: Harvard Business School Press.

Check-Teck, F. 2001. 'Designing e-logos in corporate identity strategy', Brand Management, 8(4/5):334-345.

Chen, A. C. 2001. 'Using free association to examine the relationship between the characteristics of brand association and brand equity', Journal of Product and Brand Management, 10(7):439-451.

Chen, S. K. 2001. 'Assessing the impact of the Internet on brands', Brand Management, 8(4/5):288-302.

Collins, L. 1977. 'A name to conjure with', European Journal of Marketing, 11(4/5):337-363.

Danaher, P. J., Wilson, I. W. \& Davis, R. A. 2003. 'A comparison of online and offline consumer brand loyalty', Market Science, 22(4):461-476.

De Chernatony, L. 2001. 'Succeeding with brands on the Internet', Brand Management, 8(3):186-195.

Goldstuck, A. 2002. Online retail in South Africa. Pinegowrie. World Wide Worx (Pty) Ltd.

Gulati, R. \& Garino, J. 2000. 'Get the right mix of bricks and clicks', Harvard Business Review, 78(3):107-114.

Henderson, P. W. \& Cote, J. A. 1998. 'Guidelines for selecting or modifying logos', Journal of Marketing, 62(2):14-30.

Kaikati, J. G. \& Kaikati, A. M. 2003. 'A rose by any other name: Rebranding campaigns that work'. Journal of Business Strategy, 24(6):17-23.

Kaufman-Scarborough, C. \& Lindquist, J. D. 2002. 'Eshopping in a multiple channel environment', Journal of Consumer Research, 19(4):333-350.

Keller, K. L. 1993. 'Conceptualizing, measuring, and managing customer-based brand equity', Journal of Marketing, 57(1):1-22.

Keller, K. L. 1999. 'Brand mantras: Rationale, criteria and examples', Journal of Marketing Management, 15(1-3): 4351.

Keller, K. L. 2000. 'The brand report card', Harvard Business Review, 78(1):147-157.

Keller, K. L. 2002. 'Three questions you need to ask about your brand', Harvard Business Review, 80(9):80-86.
Keller, K. L. 2003. Strategic branding management: Building, measuring, and managing brand equity. $2^{\text {nd }}$ Edition. Upper Saddle River: Prentice Hall.

Keller, G. \& Warrack, B. 2003. Statistics for management and economics. $6^{\text {th }}$ Edition. Pacific Grove: Thomson Learning.

Kotler, P. 2003. Marketing management $11^{\text {th }}$ Edition. Upper Saddle River: Pearson Education.

Kotler, P. \& Armstrong, G. 2004. Principles of marketing. $10^{\text {th }}$ Edition. Upper Saddle River: Pearson Education.

Kruger, H. \& Fourie, L. C. H. 2003. 'An investigation into the uniformity and non-uniformity of online/offline retail brand building in South Africa', South African Journal of Business Management, 34(4):27-34.

Li, Z. G. \& Gery, N. 2000. 'E-tailing - for all products?', Business Horizons, 43(6): 49-54.

Low, G. S. \& Lamb, C. W. J. 2000. 'The measurement and dimensionality of brand associations', Journal of Product and Brand Management, 9(6):350-368.

Mohammed, R. A., Fisher, R. J., Jaworski, B. J., \& Paddison, G. J. 2003. Internet marketing: Building advantage in the networked economy $2^{\text {nd }}$ Edition. New York: McGraw-Hill.

Murphy, P. E. \& Enis, B. M. 1986. 'Classifying products strategically', Journal of Marketing, 50(3):24-42.

Perea y Monsuwé, T., Dellaert, B. G. C. \& De Ruyer, K. 2004. 'What drives consumers to shop online? A literature review', International Journal of Service Industry Management, 15(1):102-121.

Peterson, A. R., Balasubramanian, S. \& Bronnenberg, B. J. 1997. 'Exploing the implications of the Internet for consumer marketing', Journal of the Academy of Marketing Science, 25(4):329-346.

Phau, I. \& Poon, S. M. 2000. 'Factors influencing the types of products and services purchased over the Internet', Internet Research: Electronic Networking Applications and Policy, 10(2):102-113.

Robertson, K. 1989. 'Strategically desirable brand name characteristics', Journal of Consumer Marketing, 6(4):6171.

Rowley, J. 2004. 'Online branding', Online Information Review, 28(2):131-138.

Rubinstein, H. \& Griffiths, C. 2001. 'Branding matters more on the Internet', Journal of Brand Management, 8(6):394404.

Saunders, M., Lewis, P. \& Thornhill, A. 2003. Research methods for business students. 3rd Edition. Essex: Pearson Education. 
Stasoft Inc. 2004. STATISTICA (data analysis software system). Version 7: Stasoft Inc.

Steyn, A. G. W., Smit, C. F. \& Du Toit, S. H. C. 1989. Moderne statistiek vir die praktyk. $4^{\text {th }}$ Edition. Pretoria: J.L. Van Schaik.

Vijayasarathy, L. R. 2002. 'Product characteristics and Internet shopping intentions', Internet Research: Electronic Networking Applications and Policy, 12(5):411-426.

Ward, M. R., \& Lee, M. J. 2000. 'Internet shopping, consumer search and product branding', Journal of Product and Brand Management, 9(1):6-20.

Willcocks, L. P. \& Plant, R. 2001. 'Getting form bricks to clicks', MIT Sloan Management Review, 42(3):50-59.

Zhan, G. L. \& Gery, N. 2000. 'E-tailing - for all products?', Business Horizons, 43(6):49-54. 